\title{
Angiographic Risk Factors of Luminal Narrowing After Coronary Balloon Angioplasty Using Balloon Measurements to Reflect Stretch and Elastic Recoil at the Dilatation Site
}

\author{
Benno J. Rensing, MD, Walter R. M. Hermans, MD, Jeroen Vos, MD, Kevin J. Beatt, MD, \\ Patrick Bossuyt, MSC, Wolfgang Rutsch, MD, and Patrick W. Serruys, MD, PhD, \\ on behalf of the CARPORT Study Group
}

Because many ongoing clinical restenosis prevention trials are using quantitative angiography to assess whether a drug is capable of reducing the amount of intimal hyperplasia, quantitative angiographic risk factors for angiographic luminal narrowing after balloon angioplasty were determined, including stretch and elastic recoil at the dilatation site. Quantitative analysis was performed on 666 lesions in 575 patients during angioplasty and at 6-month follow-up. Stretch was defined as balloon diameter minus minimal luminal diameter (MLD) before angioplasty/reference diameter, and recoil as balloon diameter minus MLD after angioplasty/reference diameter. Multivariate analysis was used to yield independent risk factors for luminal narrowing at follow-up. Predictors of absolute change in MLD were (1) relative gain at angioplasty (gain in millimeters normalized for reference diameter) and (2) lesion length. To allow risk stratification, logistic regression analysis was applied using the decrease in MLD as a binary outcome variable. A decrease in MLD at follow-up of $\geq 0.72 \mathrm{~mm}$ was considered significant. Variables retained in the model were: relative gain $>0.3 \mathrm{~mm}$ (rate ratio 2.9), relative gain 0.2 to 0.3 (rate ratio 2.1 ), stenosis length $\geq 6.8$ (rate ratio 1.7 ), and thrombus after angioplasty (rate ratio 2.6). Although stretch was significantly related to luminal narrowing at univariate analysis, it was not retained in the multivariate models.

A large gain in lumen diameter at angioplasty, dilation of long lesions, and angiographically determined thrombus after angioplasty were found to be accompanied by more severe luminal narrowing at follow-up.

(Am J Cardiol 1992;69:584-591)

From the Thoraxcenter and Center for Clinical Decision Analysis, Erasmus University, Rotterdam, the Netherlands; the Unit of Cardiovascular Medicine, Charing Cross Hospital, London, United Kingdom; and the Division of Cardiology, University of Berlin, Berlin, Germany. Manuscript received September 27, 1991; revised manuscript received October 29, 1991, and accepted October 30.

Address for reprints: Patrick W. Serruys, MD, PhD, Catheterization Laboratory, Thoraxcenter, Erasmus University, P.O. Box 1738, 3000 DR Rotterdam, the Netherlands.

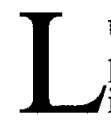

uminal narrowing after coronary balloon angioplasty still hampers the long-term vessel patency in a substantial percentage of patients. Several investigators have sought predictors of this untoward event. ${ }^{1}$ A multitude of patient-, procedural- and lesionrelated variables have been found to predict long-term outcome of an angioplasty procedure, but because these findings are based on different restenosis criteria and varying angiographic follow-up rates accurate comparison is difficult. ${ }^{2}$

Conventionally, restenosis is determined by followup angiography. Computer-assisted automated edge detection techniques enhance objectivity and reproducibility, and reduce the high inter- and intraobserver variability inherent to visual interpretation of the coronary cineangiogram. ${ }^{3}$ Because many ongoing clinical restenosis prevention trials are using quantitative angiography to assess whether a pharmacologic agent is capable of reducing the amount of intimal hyperplasia (the underlying cause of restenosis), it is important to determine quantitative angiographic risk factors for angiographic luminal narrowing after balloon angioplasty. At the moment it is unknown which angiographic parameters are associated with an increased risk for luminal narrowing. Both over- and underdilating are reported to be associated with an increased risk for restenosis. Overdilation may trigger an excessive hyperplastic response, because of its relation with dissection and deep arterial injury with increased platelet activation. ${ }^{4,5}$ Strctching of the vessel itself may also be an important stimulus for the fibroproliferative vessel reaction by being a determinant of medial smooth muscle injury ${ }^{6}$ and by changing the phenotype of the medial smooth muscle cells from contractile to synthetic. ${ }^{7}$ Elastic recoil after balloon deflation has (at least theoretically) ${ }^{8,9}$ been linked to luminal narrowing at follow-up. Underdilation may leave a significant residual stenosis with a possible increased turbulence, platelet activation and restenosis. ${ }^{10}$

In this study, quantitative lesion measurements before and after angioplasty, and at follow up were obtained and correlated with loss in minimal luminal diameter (MLD) at follow-up. To examine the effect of degree of arterial stretching and elastic recoil on luminal narrowing at follow-up, balloon diameters were measured. Stretch was defined as the difference in mean balloon diameter and MLD before angioplasty, ${ }^{6}$ and elastic recoil as the difference between mean 
balloon diameter and MLD after angioplasty. ${ }^{9}$ Both stretch and recoil were normalized for reference diameter to correct for the influence of vessel size and are therefore dimensionless.

\section{METHODS}

The study population consisted of 697 patients who were originally enrolled in 6 European centers for the CARPORT trial ${ }^{11}$ (see Appendix). In this randomized, double-blind, placebo-controlled trial, a novel thromboxane $A_{2}$ receptor antagonist (GR32191) was investigated for its ability to prevent restenosis after primary coronary angioplasty. Follow-up of these patients was performed on a prospective basis, and all patients agreed to undergo repeat angiography at 6 months. Neither angiographic nor clinical benefit of the compound could be demonstrated, ${ }^{11}$ so the placebo and active treatment groups could be pooled for the present study. All patients with both stable and unstable angina, and angiographically proven native coronary artery disease who were scheduled for primary angioplasty were considered for participation in the trial. Specific exclusion criteria are listed in Table I. A screening log was maintained at 2 centers to assess the relative frequencies of these exclusion criteria.

Unsuccessful angioplasty procedures occurred in 48 patients (6.9\%). Successful angioplasty was defined as $<50 \%$ residual stenosis by visual inspection of the angiogram after angioplasty, and no occurrence of in-hospital complications (death, acute myocardial infarction, repeat angioplasty, aortocoronary bypass grafting or recurrence of symptoms).

Five hundred seventy-five $(88.6 \%)$ of the $649 \mathrm{pa}-$ tients with a successful angioplasty had a follow-up angiogram suitable for quantitative angiography. Reasons for not completing the study were late death $(n=2)$, contraindication for repeat catheterization $(n=18)$, and refusal $(n=46)$. Eight follow-up angiograms were unsuitable for quantitative analysis.

Angioplasty procedure and follow-up angiography: Coronary angioplasty was performed with a steerable, movable guidewire system by the femoral route. Standard available balloon catheters were used. Choice of balloon type and brand, as well as inflation duration and pressure, were left to the discretion of the angioplasty operator. At the beginning of the angioplasty procedure, all patients received 10,000 IU of intravenous heparin for the first 2 hours; afterward, they received $5,000 \mathrm{IU} /$ hour for as long as the procedure continued. All patients received $10 \mathrm{mg}$ of nifedipine every 2 hours for the first 12 hours after angioplasty. Thereafter they received $20 \mathrm{mg}$ of slow-release nifedipine tablets 3 times during the second day after angioplasty.

Four coronary angiograms were obtained in each patient, 1 just before angioplasty, 1 during maximal inflation of the largest balloon used, 1 immediately after the procedure, and 1 at follow-up. Angiograms were recorded in such a way that they were suited for quantitative analysis by the Cardiovascular Angiography Analysis System (CAAS). All necessary details of the procedure were recorded, and drawings of the segments to be analyzed were made. For calibration purposes, catheter tips

\begin{tabular}{|lc|}
\hline \multicolumn{2}{|l|}{ TABLE I Reasons for Exclusion of 1,318 of 1,614 Screened } \\
Patients in Two of Six Participating Centers \\
\hline \multicolumn{1}{|c|}{ Reason } & No. (\%) \\
\hline Insufficient lead-in time* & $235(18)$ \\
Use of platelet inhibiting drugs or nonsteroid antiinflam- & $352(27)$ \\
matory drugs in 7 days preceding study \\
Refusal to participate or undergo 6-month \\
recatheterization & $364(28)$ \\
Currently receiving oral anticoagulant drugs & \\
Angioplasty for restenosis & $119(9)$ \\
Acute myocardial infarction in 2 weeks preceding angio- & $105(8)$ \\
plasty & $52(4)$ \\
Bypass graft dilatation & $39(3)$ \\
History of obstructive airway disease & $26(2)$ \\
History of peptic disease or upper Gl bleeding & $10(1)$ \\
Previous participation in the trial & $2(0.2)$ \\
Other severe disease & $6(0.5)$ \\
Participation in other trial & $6(0.4)$ \\
History of intolerance to aspirin & $1(0.1)$ \\
Aged <21 years & $1(0.1)$ \\
Pregnant or likely to become pregnant during study & $0(0)$ \\
Total & $1,318(100)$ \\
\hline *Urgent referrals outside working hours. & \\
Gl = gastrointestinal. & \\
\hline
\end{tabular}

were cut off for later measurement with a microcaliper. To standardize the method of data acquisition and to ensure exact reproducibility of the angiographic studies, measures were obtained as described previously. ${ }^{2,12}$ All angiograms were processed and analyzed at a central core laboratory (see Appendix).

The follow-up coronary angiogram was performed after 6 months. If symptoms recurred within 6 months, coronary angiography was performed earlier. If no definite restenosis was present and follow-up time was $<4$ months, the patient was asked to undergo another coronary arteriogram at 6 months.

Quantitative angiography (Figure 1): All cineangiograms were analyzed using the CAAS that has been described and validated previously. ${ }^{13,14}$ A computer-derived reconstruction of the original arterial dimension at the site of obstruction (assuming there is no disease present) is used to define the interpolated reference diameter. The length of the obstruction is determined from the diameter function on the basis of curvature analysis and is expressed in millimeters. In addition, this technique allows for the calculation of an eccentricity index ${ }^{9}$ of the lesion. The index ranges from 0 (severely eccentric) to 1 (perfectly symmetric). Because the algorithm can not measure total occlusions, a value of $0 \mathrm{~mm}$ was substituted for the MLD. In these cases, the reference diameter after angioplasty was substituted for that before. The mean change in MLD from angiography after angioplasty to follow-up and from before to after angioplasty was derived from matched angiographic projections. Balloon artery ratio was defined as the ratio of the mean balloon diameter measured in a nonforeshortened projection and the reference diameter of the dilated segment. Three parameters were calculated that reflect the changes occurring during angioplasty (Figure 2). These were (1) stretch (mean balloon diameter minus MLD before angioplasty/reference diameter), (2) elastic recoil (mean balloon diameter minus MLD after angioplasty/reference diameter) and (3) relative 


\begin{tabular}{|lc|}
\hline TABLE II Baseline Characteristics & \\
\hline Nurnber of patients & 575 \\
Age (years) & $56 \pm 9$ \\
Men/women & $464 / 111(81 \%) /(19 \%)$ \\
Time to follow-up angiography (days) & $172 \pm 41$ \\
Number of narrowings dilated & 666 \\
Left anterior descending artery & $321(48 \%)$ \\
Left circumflex artery & $154(23 \%)$ \\
Right coronary artery & $191(29 \%)$ \\
Prior myocardial infarction & $221(38 \%)$ \\
Prior coronary bypass surgery & $15(3 \%)$ \\
Prior angioplasty at other site & $10(2 \%)$ \\
\hline
\end{tabular}

gain achieved by angioplasty (MLD after minus MLD before angioplasty/reference diameter). All 3 parameters were normalized for interpolated reference diameter to correct for vessel size and are therefore dimensionless. Intracoronary thrombus was defined as an intraluminal filling defect visible in all projections or dye staining at the site of a total occlusion (interobserver concordance rate for the assessment of intracoronary thrombus in the core laboratory $89 \%$ ).

Significant luminal narrowing: To predict significant luminal narrowing after angioplasty, we chose a cutoff point above which significant deterioration in MLD is likely. We have found a change in MLD of $\geq 0.72 \mathrm{~mm}$ to be a reliable indicator of angiographic progression of vessel narrowing., ${ }^{2,14}$ This value takes into account the limitations of coronary angiographic measurements and represents twice the long-term variability for repeat measurements of a coronary obstruction using CAAS. ${ }^{14}$ This variability reflects the long-term random variation in lesion measurements from coronary angiograms obtained at different catheterization sessions using CAAS. The use of 1 standard deviation would include $68.3 \%$ of the measurement variability, whereas the use of 2 stan-

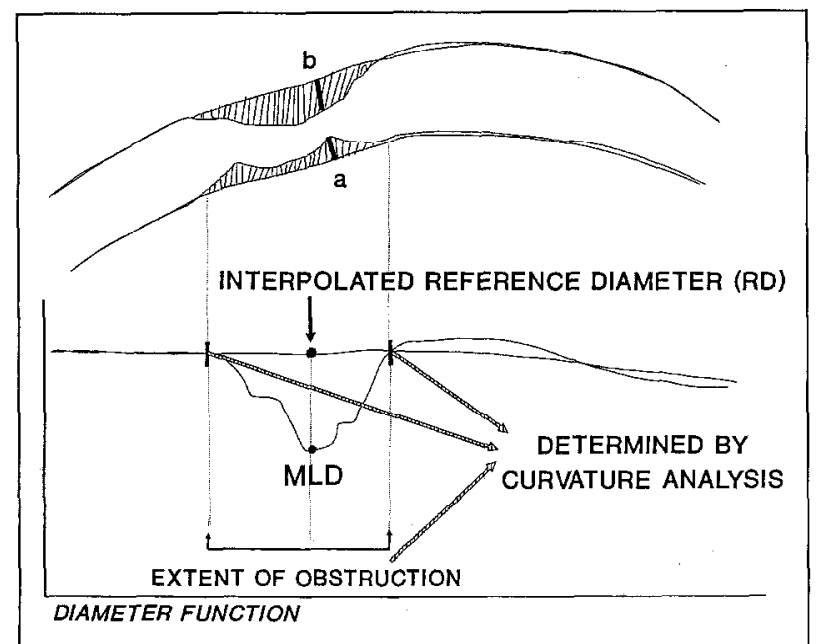

FIGURE 1. Graphic representation of quantitative angiographic measurements. Upper panel represents stenosed arterial segments. Lower panel is diameter function curve. Length of analyzed segment is depicted on $x$ axis, and vessel diameter on $y$ axis. Extent of obstruction = lesion length. Lesion length is determined with curvature analysis of descending and ascending limb of diameter function curve at site of minimal huminal diameter (MLD). Eccentricity is determined at site of MLD and calculated as $\mathbf{a} / \mathbf{b}$.

\begin{tabular}{|lc|}
\hline TABLE III Quantitative Angiographic & Data of 666 Lesions \\
\hline & Mean $\perp$ SD (range) \\
\hline Minimal luminal diameter (mm) & \\
Before anginplasty & $1.04 \pm 0.37(0.00-2.83)$ \\
After angioplasty & $1.76 \pm 0.38(0.85-3.04)$ \\
Follow-up & $1.48 \pm 0.59(0-3.15)$ \\
Diameter stenosis (\%) & $60 \pm 13(33-100)$ \\
Before angioplasty & $34 \pm 9(6-65)$ \\
After angioplasty & $45 \pm 19(4-100)$ \\
Follow-up & $0.75 \pm 0.40$ \\
Difference in minimal luminal diameter & \\
Before and after angioplasty (mm) & $0.28 \pm 0.52$ \\
After angioplasty-follow up (mm) & $0.28 \pm 0.16$ \\
Relative gain at angioplasty* & \\
Difference in \% diameter stenosis & $26 \pm 14$ \\
Before and after angioplasty (\%) & $11 \pm 19$ \\
After angioplasty-follow-up (\%) & \\
\hline *See Figure 2. & \\
\hline
\end{tabular}

dard deviations $(2 \times 0.36=0.72 \mathrm{~mm})$ includes $95.5 \%$. Therefore, a difference in MLD of more than twice the long-term measurement variability can be considered indicative of significant luminal narrowing. To compare the criterion of change in MLD with a more conventional criterion of restenosis, analyses were also performed with the $\geq 50 \%$ diameter stenosis criterion.

Data analysis: Data were analyzed using the BMDP statistical software package (University of California, Berkeley, California). In a univariate analysis (unpaired Student's $t$ test), those continuous quantitative angiographic variables that were related to a significant loss in MLD were selected. These variables together with elastic recoil and balloon artery ratio (known from the literature to be related to restenosis) were entered in a stepwise multiple linear regression analysis to identify variables, with an independent contribution to the prediction of absolute decrease in MLD as a continuous variable (see Appendix).

To allow risk stratification, logistic regression analysis using indicator variables was subsequently applied, with the decrease in MLD (using a decrease of $\geq 0.72$ $\mathrm{mm}$ as the cutoff value), and the $50 \%$ diameter stenosis

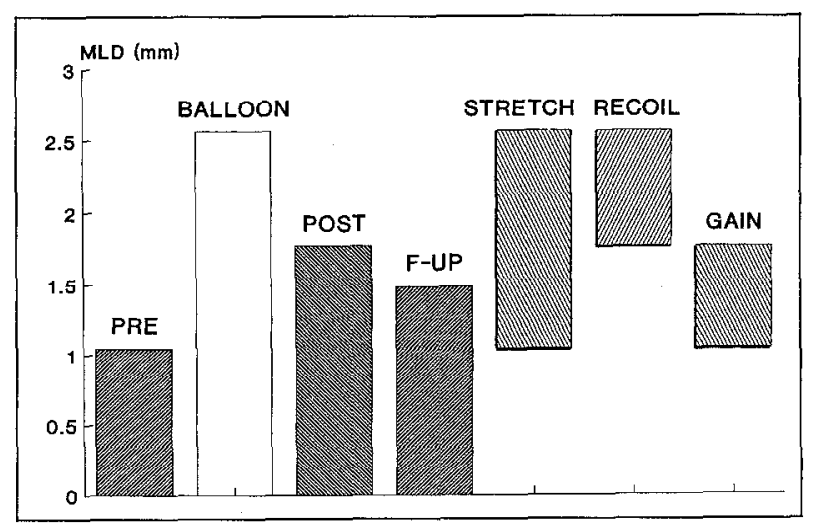

FIGURE 2. Graphic representation of terms used. Mean absolute values of variables are shown. Stretch, recoil and gain were normalized for vessel size (reference diameter) to correct for vossel size. BALLOON = balloon mean diameter; F-UP = follow-up MLD; MLD = minimal luminal diameter; POST = MLD after angioplasty; PRE = MLD before angioplasty. 
criterion as binary outcome variables, because the logistic regression coefficients are easily related to adjustedrate ratios for the different variables. Continuous variables were therefore grouped into 3 equally sized subgroups (tertiles). Three subgroups were selected to enable assessment of trends in the incidence of a $\geq 0.72$ $\mathrm{mm}$ decreasc and becausc more subgroups would wcaken the strength of associations. The incidence of a $\geq 0.72 \mathrm{~mm}$ decrease was determined in each subgroup. If a trend for a higher incidence was present in each consecutive subgroup, then the one with the lowest incidence was chosen as the reference group. If no trend for an increasing incidence of a $\geq 0.72 \mathrm{~mm}$ decrease was present in each consecutive subgroup, the one with the highest incidence was compared with the 2 others combined (reference group).

Distortion of the relation between different determinants of a $\geq 0.72 \mathrm{~mm}$ decrease in MLD and the incidence of a decrease $\geq 0.72 \mathrm{~mm}$ (confounding) caused by unequal distributions of these determinants among the tertiles was eliminated by multivariate logistic regression analysis. Description of the multivariate logistic regression model and of the methodology to obtain adjusted-rate ratios and 95\% confidence intervals (CIs) is given in the Appendix.

\section{RESULTS}

Baseline characteristics of the 575 patients with quantitative angiographic follow-up are summarized in Table II.

Overall quantitative angiographic findings before and after angioplasty, and at follow up are presented in Table III. Reference diameter was not different before and after angioplasty, and at follow up $(2.64 \pm 0.56$, $2.71 \pm 0.54$ and $2.71 \pm 0.56 \mathrm{~mm}$, respectively), suggesting an accurate control of vasomotion during the 3 angiographic studies.

The incidence of significant luminal narrowing ( $\geq$ $0.72 \mathrm{~mm}$ ) was $17.7 \%$ (117 of 666 lesions). The incidence of restenosis according to the $50 \%$ diameter stenosis criterion was $33 \%$ ( 220 of 666 lesions).

Univariate analysis: With univariate analysis (Table IV), the following quantitative angiographic variables were associated with a $\geq 0.72$ decrease in MLD: MLD before and after angioplasty, increase in MLD obtained by angioplasty, length of obstruction, and stretch. Thirty-six lesions were totally occluded before angioplasty, and therefore, stenosis length and eccentricity coefficient could not be measured. For comparison with the traditional restenosis criterion of $>50 \%$ diameter stenosis at follow-up, values were also broken down according to this criterion. The apparent difference in MLD after angioplasty for the 2 criteria, and the absence of a difference in relative gain in the $\leq$ and $>50 \%$ diameter stenosis at follow-up groups are explained later.

More stretching was accompanied by more recoil. The amount of recoil in the tertile with the highest amount of stretch $(\geq 0.65)$ was 0.42 compared with 0.25 in the other 2 tertiles combined (stretch $<0.65$ ) ( $p$ $<0.0001$; unpaired $t$ test).

Multiple linear regression analysis: The variables significantly related to a $\geq 0.72 \mathrm{~mm}$ decrease in MLD

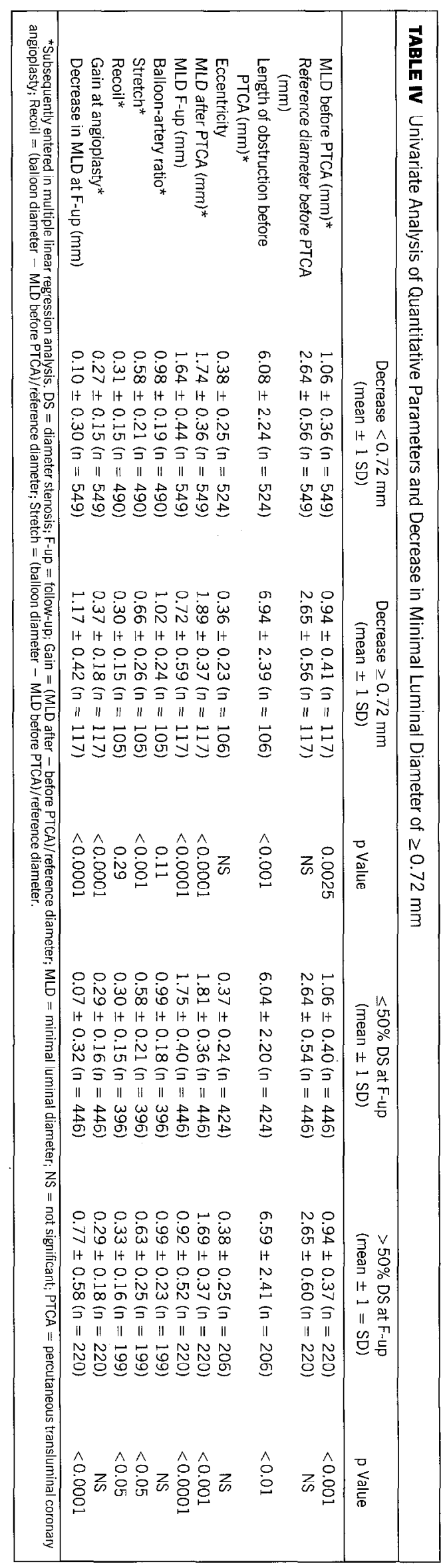

CHANGES AT ANGIOPLASTY AND RESTENOSIS 
in the univariate analysis, as well as elastic recoil and balloon artery ratio, were entered in the multiple linear regression analysis. Only relative gain in MLD at angioplasty, and the length of the stenosis were retained in the final model. The amount of stretch induced on the vessel wall, although significantly higher in the group of lesions with a $\geq 0.72 \mathrm{~mm}$ decrease in MLD with univariate analysis, was not retained in the stepwise multiple linear regression model.

Logistic regression analysis: The variables retained in the multiple linear regression analysis, and 6 variables known from the literature to be related to restenosis were entered in the logistic regression model. The latter variables were vessel dilated, ${ }^{15}$ total occlusion before angioplasty, ${ }^{16}$ angiographically determined thrombus before and after angioplasty, elastic recoil and balloon artery ratio. Thrombi before and after angioplasty were included, because it has been reported that thrombotic lesions are longer in length and that total occlusions frequently have a thrombotic component. Furthermore it is conceivable that thrombotic lesions have a larger relative gain and low elastic recoil. Angiographically, a thrombus was observed in 32 of 666 lesions before angioplasty (5\%) and in $16(1.6 \%)$ after. Type of trial medication (placebo or active treatment) was forced into the model to rule out any effect on the analysis results. Because dilation of totally occluded coronary arteries is associated with a higher restenosis rate, ${ }^{16}$ and it could be argued that in these lesions in general a higher gain at angioplasty will be achieved, this determinant was also forced into the model to account for any confounding effect. Totally occluded lesions did not have length measurements; therefore, the indicator variable for lesion length was set to 0 in these cases.

A relative gain at angioplasty of $\geq 0.3$ had an adjusted-rate ratio (RR) for developing a decrease in MLD $\geq 0.72 \mathrm{~mm}$ of 2.9 . This means that the risk for developing a decrease of $\geq 0.72 \mathrm{~mm}$ with at least this relative gain is 2.9 times as high as it is for lesions with a relative gain $<0.2$. The $95 \%$ CIs were 1.9 to 4.5 . Other variates retained were relative gain between 0.2 and 0.3 (RR 2.1, 95\% CI 1.3 to 3.3 ), lesion length $\geq 6.8 \mathrm{~mm}$ (RR 1.7, 95\% CI 1.2 to 2.3 ) and thrombus after angioplasty (RR 2.6, 95\% CI 1.1 to 6.2). Total occlusion before angioplasty and use of active trial medication had no significant independent predictive contribution to a significant decrease in MLD (RR 1.5, 95\% CI 0.8 to 3.0 , and RR 1.1, 95\% CI 0.7 to 1.5 , respectively). Stretch, balloon artery ratio, elastic recoil, type of vessel, and thrombus before angioplasty were not retained in the final logistic regression model.

To assure that total occlusions did not unduly influence the results, analysis was repeated excluding these lesions. Adjusted-rate ratios were similar to those in the original analysis (relative gain 0.2 to 0.3 : RR $2.2,95 \%$ CI 1.4 to 3.4; relative gain >0.3: RR 3.2, 95\% CI 2.0 to 5.1; lesion length $\geq 6.8 \mathrm{~mm}$ : RR $1.8,95 \%$ CI 1.2 to 2.6 ).

The logistic regression analysis was also performed with the $>50 \%$ diameter stenosis criterion as dependent variable. Type of trial medication was again forced into the model. A lesion length of $\geq 6.8 \mathrm{~mm}$ (RR $1.3,95 \%$ CI 1.1 to 1.4 ) and thrombus after angioplasty (RR 1.8 , 95\% CI 1.0 to 3.1) were retained in the final model. The use of GR32191 as trial medication had an adjustedrate ratio of 0.98 (95\% CI 0.9 to 1.1$)$.

\section{DISCUSSION}

Luminal narrowing after coronary angioplasty is a complex process that is only partially understood. Histologic studies of coronary arteries after dilation obtained by either autopsy or atherectomy have provided direct and indirect evidence that strongly supports the concept of intimal hyperplasia or proliferation of smooth muscle cells of medial or intimal origin as the underlying cause of luminal narrowing after angioplasty. ${ }^{5,17}$

The 1 factor most strongly associated with luminal narrowing in this study was the relative gain in MLD achieved by angioplasty. This probably best reflects the combination of deep arterial injury and reversible stretch imposed on the diseased vessel wall. Deep arterial injury and smooth muscle cell stretch are known stimuli for smooth muscle cell proliferation. It is now believed that after balloon injury, denudation of endothelial cells is followed by platelet adhesion and aggregation with the release of growth factors (notably platelet-derived growth factor), and vaso- and platelet-active substances. Extensive damage to the endothelial lining of the vessel, which is always present after balloon dilatation, may upset the balance between the inhibiting effect of endothelial-derived heparin sulphates on medial smooth muscle cell growth, and the mitogenic and chemotactic effect of platelet-derived growth factor and of other growth factors on these cells. ${ }^{18}$ Not only platelet exposure to the vascular layers, but also dircet injury to the smooth muscle cells is reported to begin the proliferative response. ${ }^{19}$ So, as suggested by Liu et $\mathrm{al}^{20}$ a major factor that determines the amount of intimal hyperplasia after balloon angioplasty seems to be the extent of permanent mechanical injury inflicted upon the vessel wall. Animal experiments with an atherosclerotic rabbit model have shown that the combination of balloon oversizing and long inflations caused most damage to the vessel wall and was associated with the greatest degree of intimal hyperplasia at follow-up. ${ }^{21}$ Similarly Schwartz et $\mathrm{al}^{22}$ described an aggressive proliferative response in a porcine model as a result of severe stent oversizing. This effect, which they attributed to penetration of the internal elastic membrane by the stent wires and subsequent deep arterial injury, was much less pronounced when the stent was matched more closely to the vessel diameter. This was recently also demonstrated in a clinical stent study. ${ }^{23}$ Implantation of an oversized stent was combined with a more aggressive hyperplastic reaction than when the stent was more closely matched to the receiving artery.

Dilation of totally occluded coronary arteries is known to be associated with a higher restenosis rate. ${ }^{16}$ However, total occlusions forced in the logistic regression model did not have a significant independent contribution to the prediction of a decrease in MLD of $\geq 0.72 \mathrm{~mm}$, probably due to an unequal distribution of 
thrombus after angioplasty over totally occluded and patent arteries; 6 of $36(16.7 \%)$ total occlusions before angioplasty had a thrombus after versus 10 of 630 (1.5\%) patent arteries. It could be argued that in total occlusions in general, a higher gain at angioplasty will be achieved, and that this may be the explanation for the relation found between gain and restenosis. In our population, 36 total occlusions were successfully dilated with a restenosis rate at follow-up of $33.3 \%$ ( 12 of 36 ; $\geq 0.72 \mathrm{~mm}$ critcrion). Howcver, if total occlusions bcfore angioplasty are left out of the analysis, a high relative gain and lesion length were still associated with a significant adjusted risk for a decrease of $\geq 0.72 \mathrm{~mm}$.

The fact that angiographically determined thrombus at the dilation site before angioplasty was not found to be a risk factor for a significant decrease in MLD tends to confirm our earlier report that showed no difference in significant luminal narrowing for patients with unstable angina. ${ }^{24}$ Angiographically demonstrable intracoronary thrombus after angioplasty is the angiographic proof that massive platelet aggregation, thrombin activation and fibrin formation have occurred with the subsequent release of vasoactive substances ${ }^{25}$ and growth factors involved in the fibroproliferative restenosis process. Furthermore, a recent postmortem study showed that part of early ( $<1$ month) restenosis lesions consisted of mural thrombus. 5

Longer lesions were found to be associated with a higher relative risk for restenosis at follow-up. In these lesions, more smooth muscle is possibly exposed to injury and platelet adhesion, which enhances the risk of restenosis. Several studies have indeed shown that long lesions and vessel areas containing thick atherosclerotic plaques are related to an increased incidence of dissections, and thus more extensive vessel wall injury. ${ }^{26,27}$

Several experimental studies have suggested that dilation of the vessel wall is a stimulus for smooth muscle cell proliferation and later intimal hyperplasia, ${ }^{19,21}$ either by stretch or direct injury to smooth muscle cells. In the present study, univariate analysis (Table IV) showed that a significantly higher amount of stretch was induced on the vessel wall in the group with a $\geq 0.72 \mathrm{~mm}$ decrease in MLD. These findings correlate with the observations by Fischell et $\mathrm{al}^{6}$ that showed a relation between the degree of arterial stretching and the severity of smooth muscle injury as determined by reduction of vasoconstrictor responsiveness and by histopathological examination, and, as emphasized previously, more smooth muscle injury has been shown to enhance intimal hyperplasia in a more controlled animal model. ${ }^{21}$ I Iowever, after elimination of the unequal distribution of stretch over the various determinants of a significant decrease in MLD by multivariate analysis, stretch was not found to be an independent predictor of luminal narrowing.

Elastic recoil, as measured within minutes after the last dilatation, ${ }^{9}$ was not found to be a determinant of restenosis. This finding is at variance with another report $^{8}$ that suggests that recoil may be a factor in luminal narrowing observed at follow-up. It may be that recoil is not an instantaneous phenomenon, but rather ex- erts its effect over a longer period of time, and thus could not be picked up by the angiogram after angioplasty that was obtained within minutes after the final balloon deflation.

Study limitations: To allow risk stratification for decrease in MLD with the use of multivariate analysis techniques, a cutoff point had to be chosen that accurately describes those lesions that underwent a significant deterioration at follow-up. The rationale for the $0.72 \mathrm{~mm}$ criterion as a marker for significant luminal narrowing is outlined previously. This criterion is not meant to be a restenosis criterion in this study, because that also implies some sort of functional measure of lesion severity at follow-up. The frequently used definition of $50 \%$ diameter stenosis at follow-up is historically based on the physiologic concept of coronary flow reserve introduced by Gould et $\mathrm{al}^{28}$ in 1974 and is used because it represents the approximate value in animals with normal coronary arteries at which blunting of the hyperemic response occurs. Although this value may be of some relevance in determining a significant stenosis in human atherosclerotic vessels, it tells us nothing about the dynamic behavior of the restenosis process. If the $50 \%$ diameter stenosis at follow-up criterion is used, lesions with a suboptimal angioplasty result will preferentially be selected (i.e., have to undergo a small decrease in MLD to be termed restenosed). This is reflected by the lower MLD after angioplasty in the $>50 \%$ diameter stenosis group (Table IV) compared with that of the $>50 \%$ group. The mean percent diameter stenosis after angioplasty in the group with a relative gain $<0.2$ was $40 \%$; in the group with a relative gain between 0.2 and 0.3 this was $34 \%$, and in that with a gain $\geq 0.3$ this was $28 \%$. This means that lesions with a small relative gain generally tend to have a poorer result after angioplasty and are close to the $50 \%$ diameter stenosis cutoff point. Furthermore, because the long-term variability of diameter stenosis measurements using CAAS is $6.5 \%,{ }^{14}$ a significant number of lesions will be defined as restenosed, while in fact no change has occurred. The mean percent diameter stenosis after angioplasty was $31 \%$ for those lesions fulfilling the $\geq 0.72 \mathrm{~mm}$ criterion, and $37 \%$ for the $>50 \%$ diameter stenosis criterion. Therefore, both criteria describe different populations at follow-up, and if one wants to examine risk factors for change in luminal diameter, the $50 \%$ diameter stenosis criterion is inappropriate.

The definition of stretch was essentially the same as that used by Fischell et $\mathrm{a}^{6}$ in a series of in vitro experiments with isolated, perfused, nondiseased, whole vessel segments of rabbit aortas and dog carolid arteries. In our population of diseased arterial segments, stretch was calculated as the difference between mean balloon diameter and MLD before angioplasty divided by the relaxed reference diameter, because this reflects the maximal focal stretch induced on the vessel wall. This presumes that no compression or extrusion of the atherosclerotic plaque occurred during angioplasty.

The immediate luminal narrowing after balloon deflation that we attributed to elastic recoil could also be caused by spasm or nonocclusive mural thrombus for- 
mation. It has been shown that the administration of intracoronary nitrates after angioplasty abolishes possible spasm. ${ }^{19,29}$ Furthermore, the mean reference diameter after angioplasty was not different from that before. Our angiogram after angioplasty was obtained within minutes after the final balloon deflation, and although we cannot rule out the possibility of mural thrombus to occur in this short time period, we believe that it cannot explain the observed immediate 30\% reduction in MLD.

Acknowledgment: The logistic and technical support of Jaap Pameijer, RN, is greatly appreciated. We thank Jaap W. Deckers, MD, and Alfred E.R. Arnold, MD, for critical comments and methodologic advice.

\section{APPENDIX}

Linear regression analysis: Stepwise multiple linear regression analysis was performed (BMDP statistical package, program $2 \mathrm{R}$ ) to assess the relation between the variables mentioned in Methods (independent variables $=X_{i}$ ) and the decrease in MLD from the angiogram before angioplasty to that at follow-up (dependent variable $=\mathrm{Y}$ ): $\mathrm{Y}=\mathrm{A}+\Sigma_{\mathrm{i}} \mathrm{B}_{\mathrm{i}} \mathrm{X}_{\mathrm{i}}$, where $\mathrm{A}$ is the intercept and $B_{i}$ is the th regression coefficient. The standard $2 R$ criteria of $F>4$ for inclusion, and $F<3.9$ for elimination were used.

Multivariate logistic regression analysis: Multiple logistic regression analysis was performed with the BMDP statistical package (program LR). The linear logistic model relates a probability $(\mathrm{P})$ for the outcome event to the value of a baseline characteristic (X) using the linear logistic function: $P=1 / 1+e^{-(a+b X)}$. The relation between variables retained in the multiple linear regression model and restenosis according to the 0.72 $\mathrm{mm}$ criterion was expressed in a multivariate logistic regression model. Also, a set of variables reported to be predictors of restenosis was selected. All these variables were entered in a model, 1 at a time. The model to describe the risk for developing restenosis was fitted to the data of 595 lesion dilatations with balloon measurements. The standard LR criteria of $p<0.1$ for inclusion, and $p>0.15$ for elimination were used. Adjusted-rate ratios and $95 \%$ confidence intervals were obtained according to the method of Miettinen ${ }^{30}$ by the following formulas, in which the incidence of restenosis was entered for all variates $\left(X_{i}\right)$ other than the variates for which the adjusted-rate ratio was determined; 1 was entered for the variate under study $\left(X_{j}\right)$ in the numerator and 0 in the denominator:

Rate ratio $=\frac{\left[1+\exp \left(-\left(\text { intercept }+\Sigma_{\mathrm{i}} \mathrm{b}_{\mathrm{i}} X_{\mathrm{i}}+\mathrm{b}_{\mathrm{i}} 1\right)\right)\right]^{-1}}{\left[1+\exp \left(-\left(\text { intercept }+\Sigma_{\mathrm{i}} \mathrm{b}_{\mathrm{i}} X_{\mathrm{i}}+\mathrm{b}_{\mathrm{j}} 0\right)\right)\right]^{-1}}$

$95 \%$ confidence interval: rate ratio ${ }^{(1 \pm 1.96 /(\mathrm{bj} / \mathrm{SE}))}$.

The following people and institutions form the CARPORT (Coronary Artery Restenosis Prevention On Repeated Thromboxane-antagonism) study group.

Clinical centers: Thoraxcenter (Rotterdam, the Netherlands): Patrick W. Serruys, MD, ${ }^{* \dagger}$ Benno J. Rensing, MD, Hans E. Luijten, MD, Pim J. de Feyter, MD, Haryanto Suryapranata, MD, Marcel van den Brand, MD; Jos R.T.C. Roelandt, MD; Klinikum
Charlottenburg (Berlin, Germany): Wolfgang Rutsch, MD,* Maria Klose, MD; C.H.R.U de Nancy-Hopitaux de Brabois (Nancy, France): Nicolas Danchin, MD,* Yves Juilliere, MD, A. Hueber, MD, Francois Cherrier, MD; Onze Lieve Vrouw Ziekenhuis (Aalst, Belgium): Guy R. Heyndrickx, MD,* Paul Nellens, MD, Bernard de Bruyne, MD, Marc Goethals, MD, Peter Goemare, $\mathrm{RN}$; St. Antonius Ziekenhuis (Nieuwegein, the Netherlands): E. Gijs Mast, MD,* Fokke A.M. Jonkman, MD, R. Melvin Tjon Joe Gin, MD; U.C.L. St. Luc University Hospital (Brussels, Belgium): William Wijns, MD,* M. Delgadillo, Jean Renkin, MD.

Quantitative angiographic core laboratory: Cardialysis/Thoraxcenter (Rotterdam, the Netherlands): Patrick W. Serruys, MD, Benno J. Rensing, MD, Walter R.M. Hermans, MD, Jaap Pameijer.

Data coordinating center: Socar SA (Givrins, Switzerland): Jeroen Vos, MD, Marianne Bokslag, Jacobus Lubsen, MD.

Glaxo Group Research Ltd (Greenford, Middlesex, United Kingdom): Anthony McAllister, $\mathrm{PhD}$, Michael Perelman, MD.

\section{REFERENCES}

1. Serruys PW, Rensing BJ, Luijten HE, Hermans WRM, Beatt KJ. Restenosis following coronary angioplasty. In: Meier B, ed. Interventional Cardiology. Bern, Switzerland: Hogrefe and Huber, 1990:79-115.

2. Serruys PW, Luijten HE, Beatt KJ, Geuskens R, de Feyter PJ, van den Brand M, Reiber JHC, Ten Katen HJ, van Es GA, Hugenholtz PG. Incidence of restenosis after successful coronary angioplasty: a time related phenomenon. A quantitative angiographic study in 342 consecutive patients at 1, 2, 3 and 4 months. Circulation 1988;77:361-371.

3. Meier B, Grüntzig AR, Goebel N, Pyle R, von Gosslar W, Schlumpf M. Assessment of stenoses in coronary angioplasty: inter- and intraobserver variability. Int J Cardiol 1983;2:159-169.

4. Lam JYT, Chesebro JH, Steale PM, Dewanjee HK, Badimon I, Fuster V. Deep arterial injury during experimental angioplasty: relation to a positive indium-111 labeled scintigram, quantitative platelet deposition and mural thrombus. $J$ Am Coll Cardiol 1986;8:1380-1386.

5. Nobuyoshi M, Kimura T, Ohishi H, Horiuchi H, Nosaka H, Hamasaki N, Yokoi H, Koutaku K. Restenosis after percutaneous transiluminal coronary angioplasty: pathologic observations in 20 patients. $\mathrm{J} \mathrm{Am} \mathrm{Coll} \mathrm{Cardiol} \mathrm{1991;17:}$ 433-439.

6. Fischell TA, Grant G, Johnson DE. Determinants of smooth muscle injury during balloon angioplasty. Circulation 1990;82:2170-2184.

7. Campbell GR, Campbell JH. Smooth muscle cell phenotype changes in arterial wall homeostasis: implications for the pathogenesis of atherosclerosis. Exp Mol Path 1985;42:139-162.

8. Waller BF. "Crackers, breakers, stretchers, drillers, scrapers, shavers, burners, welders and melters." The future treatment of coronary artery disease? A clinicalmorphologic assessment. J Am Coll Cardiol 1989;13:969-987.

9. Rensing BJ, Hermans WRM, Beatt KJ, Laarman GJ, Suryapranata H, van den Brand M, De Feyter PJ, Serruys PW. Quantitative angiographic assessment of elastic recoil after percutaneous transluminal coronary angioplasty. $\mathrm{Am} \mathrm{J}$ Cardiol 1990;66:1039-1044.

10. Hardoff $R$, Shefar A, Gips S, Mardlar A, Flugelman MY, Halon DA, Lewis BS. Predicting late restenosis after coronary angioplasty by very early ( 12 to 24 hours) thallium-201 scintigraphy: implications with regard to late restenosis. $J$ Am Coll Cardtol 1990;15:1486-1492.

11. Serruys PW, Rutsch W, Heyndrickx GR, Danchin N, Mast EG, Wijns W, Rensing BJ, Vos J, Stibbe J. Prevention of restenosis after percutaneous transluminal coronary angioplasty with thromboxane A2 receptor blockade. A randomized, double blind, placebo controlled trial. Circulation 1991:84:1568-1580.

12. Reiber JHC, Serruys PW, Kooyman CJ, Slager CJ, Schuurbiers JHC, Boer A den. Approaches toward standardization in acquisition and quantitation of arterial dimensions from cineangiograms. In: Reiber JHC, Serruys PW, eds. State of the Art in Quantitative Coronary Angiography. Dordrecht, the Netherlands: Martinus Nijhoff, 1986:145-155.

13. Reiber JHC, Serruys PW. Quantitative angiography. In: Matcus ML, Schelbert HR, Skorton DJ, Wolf GL, eds. Cardiac Imaging, a Companion to Braunwalds Heart Disease. New York: W.B. Saunders, 1991:211-280.

\footnotetext{
*Principle investigator; ${ }^{\dagger}$ chairman of steering committee.
} 
14. Reiber JHC, Serruys PW, Kooyman CJ, Wijns W, Slager CJ, Gerbrands JJ, Schuurbiers JCH, den Boer A, Hugenholtz PG. Assessment of short, medium and long term variations in arterial dimensions from computer assisted quantification of coronary cineangiograms. Circulation 1985;71:280-288.

15. Leimgruber PP, Roubin GS, Hollman J, Cotsonis GA, Meier B; Douglas JS, King SB III, Grüntzig AR. Restenosis after successful coronary angioplasty in patients with single-vessel disease. Circulation 1986;73:710-717.

16. Serruys PW, Umans V, Heyndrickx GR, Brand $M$ van den. Feyter PJ de, Wijns W, Jaski B, Hugenholtz PG. Elective PTCA of totally occluded coronary arteries not associated with acute myocardial infarction; short-term and long-term results. Eur Heart $J$ 1985;6:2-12.

17. Safian RD, Gelbish JS, Erny RE, Schnitt SJ, Schmidt D, Baim DS. Coronary atherectomy: clinical, angiographic and histologic findings and observations regarding potential mechanisms. Circulation 1990;82:69-79.

18. Campbell GR, Campbell JH. Phenotypic modulation of smooth muscle cells in primary culture. In: Campbell JH, Campbell GR, eds. Vascular Smooth Muscle in Culture. Boca Raton, FLA: CRC Press, 1987:39-55.

19. Guyton JR, Karnovsky MJ. Smooth muscle cell proliferation in the occluded rat carotid artery. Lack of requirement for luminal platelets. Am J Pathol 1979:94:585-602.

20. Liu MW, Roubin GS, King SB III. Restenosis after coronary angioplasty. Potential biologic determinants and role of intimal hyperplasia. Circulation 1989;79:1374-1387.

21. Sarembock IJ, La Veau PJ, Sigal SL, Timms I, Sussman J, Haudenschild C, Ezekowitz MD. Influence of inflation pressure and balloon size on the development of intimal hyperplasia after balloon angioplasty. A study in the atherosclerotic rabbit. Circulation 1989;80:1029-1040.

22. Schwartz RS, Murphy JG, Edwards WD, Camrud AR, Vlietstra RE,
Holmes DR. Restenosis after balloon angioplasty. A practical proliferative model in porcine coronary arteries. Circulation 1990;82:2190-2200.

23. Strauss BH, Serruys PW, de Scheerder IK, Tijssen JGP, Bertrand ME, Pue JP, Meier B, Kaufman U, Stauffer JC, Rickards AF, Sigwart U. A relative risk analysis of the angiographic predictors of restenosis in the coronary wallstent. Circulation 1991;84:1636-1643.

24. Luijten HE, Beatt KJ, de Feyter PJ, van den Brand M, Reiber JHC, Serruys PW. Angioplasty for stable versus unstable angina: are unstable patients more likely to get restenosis? A quantitative angiographic study in 339 consecutive patients. Int I Card Imaging 1988;3:87-97.

25. Zeiher AM, Schächinger V, Weitzel SH, Wollschläger H, Just H. Intracoronary thrombus formation causes focal vasoconstriction of epicardial arteries in patients with coronary artery disease. Circulation 1991;83:1519-1525.

26. Zolikofer C, Chain J, Salomonowitz E, Runge W, Bruehlman W, Castaneda-Zuniga W, Amplatz K. Percutaneous transluminal angioplasty of the aorta. Radiology 1984;151:355-363.

27. Ellis SG, Roubin GS, King III SB, Weintraub JS, Thomas RG, Cox WR. Angiographic and clinical predictors of acute closure after native vessel coronary angioplasty. Circulation 1988;77:372-379.

28. Gould KL, Lipscomb K, Hamilton GW. Physiologic basis for assessing critical stenoses: instantaneous flow response and regional distribution during coronary hyperemia as measures of coronary flow reserve. Am $J$ Cardiol 1974;33:87-94.

29. Fischell TA, Derby G, Tse TM, Stadius ML. Coronary artery vasoconstriction routinely occurs after percutaneous transluminal coronary angioplasty. A quantitative arteriographic analysis. Circulation 1988;78:1323-1334.

30. Mietinnen OS. Theoretical Epidemiology: Principles of Occurrence Research in Medicine. New York: John Wiley \& Sons, 1985:235. 